NASA Technical Memorandum 103802

\title{
A Seven Patch Hexagonal CP Subarray With a CPW/Stripline Feed Network
}

R.N. Simons

Sverdrup Technology, Inc.

Lewis Research Center Group

Brook Park, Ohio

R.Q. Lee and G. R. Lindamood

National Aeronautics and Space Administration

Lewis Research Center

Cleveland, Ohio

Prepared for the

1991 North American Radio Science Meeting and International IEEE/AP-S Symposium

London, Ontario, Canada, June 24-28, 1991 


\title{
A SEVEN PATCH HEXAGONAL CP SUBARRAY WITH CPW/STRIPLINE FEED NETWORK
}

\author{
R.N. Simons \\ Sverdrup Technology, Inc. \\ Lewis Research Center Group \\ Brook Park, Ohio 44142 \\ R.Q. Lee \\ National Aeronautics and Space Administration \\ Lewis Research Center \\ Cleveland, Ohio 44135 \\ G.R. Lindamood* \\ University of Akron \\ Akron, Ohio 44325
}

\begin{abstract}
A seven element microstrip subarray of hexagonal geometry has been designed and tested at s-band frequencies. The microstrip patch antenna is excited at a single feed position using a direct probe type connection to generate a circularly polarized (CP) wave. The RF power is coupled to these feed positions by a novel coplanar waveguide/stripline feeding network. The paper describes the subarray architecture and the feed network in detail. The measured results include the feed network characterization as well as the radiation patterns of the subarray.
\end{abstract}

\section{INTRODUCTION}

Microstrip patch antennas have many salient features such as low cost, light weight, thin profile, conformability and ease of fabrication which makes them attractive for satellite communications applications. These antennas can be excited to radiate linearly polarized or circularly polarized (CP) waves using only a single feed. For linear polarization, a rectangular patch antenna is excited with the feed located near the center of one edge to achieve proper impedance matching. To generate CP waves without the use of phase shifters or hybrid couplers, a nearly square patch must be used with the feed position determined as given in [1].

This paper describes the architecture of a seven patch hexagonal CP planar subarray (Fig.1). The seven patches are fed in equal amplitude and phase by a novel probe type feed network. The feed is formed by a multilayer network which is realized using a combination of coplanar waveguide ( $\mathrm{CPW}$ ) and balanced stripline.

* Summer Student Intern at NATA Lewis Research Center. 


\section{FEED SYSTEM DESIGN AND PERFORMANCE}

The feed system consists of a 7-way radial CPW power divider network [2], a balanced stripline line stretcher and a CPW to stripline coupler. The RF power to the radial CPW power divider network (Fig.2) is fed by a coaxial line. The axis of the coaxial line and the plane of the CPW circuit are orthogonal. Thus the inner conductor of the coaxial line meets the junction formed by the intersecting center strip conductors of the CPW. The outer conductor of the coaxial line is slotted and meets the ground planes of the CPW. In this manner, the seven radial CPW lines are excited in equal amplitude and phase [2]. The measured return loss at the coaxial input port, the power coupled to any one of the seven output ports and the isolation between any two output ports are shown in Figures 3(a) thru 3(c). At the design frequency of $2.2875 \mathrm{GHz}$, the measured insertion loss is only 0.15 $\mathrm{dB}$ more than the $8.45 \mathrm{~dB}$ theoretically expected for $a$ seven way divider. The return loss and the isolation are better than $10 \mathrm{~dB}$ and $15 \mathrm{~dB}$ respectively.

The output signal from the power divider is coupled to a balanced stripline line stretcher by a post coupler. The line stretcher equalizes the path length to each of the seven patch antennas. Finally, the signal from the line stretcher is coupled to the patch antennas by a second post coupler which also works as a probe feed. Figure $4(\mathrm{a})$ shows a CPW to a balanced stripline post coupler. In this coupler, the center strip conductor of the CPW and the strip conductor of the stripline are electrically connected by a metal post. The metal post enters the stripline through an aperture in the ground plane. The ground plane of the $\mathrm{CPW}$ and the stripline are connected together by bond wires and shorting pins. The preliminary measured characteristics of the coupler are presented in Figure $4(\mathrm{~b})$. The insertion loss and return loss of the coupler are about $0.4 \mathrm{~dB}$ and $12 \mathrm{~dB}$ at 2.2875 $\mathrm{GHz}$.

\section{SUBARRAY DESIGN AND PERFORMANCE}

The patches $(4.45 \times 4.39 \mathrm{cms})$ are arranged in a triangular lattice to form a hexagonal geometry with an edge to edge spacing of 0.43 inches. The assembled subarray and the feed and power divider network are shown in Figs. 5(a) and 5(b) respectively. The measured radiation patterns of the array at $2.325 \mathrm{GHz}$ for the $\phi=0^{\circ}$ and $\phi=90^{\circ}$ planes are shown in Figs. 6(a) and 6(b) respectively. The measured on axis axial ratio for the LHCP is $1.5 \mathrm{~dB}$ and the $3 \mathrm{~dB}$ beam widths are $36^{\circ}$ in both planes. The gain of the antenna as determined from the beam widths is $13 \mathrm{~dB}$. The measured return loss at the coaxial input port of the array is better than $15 \mathrm{~dB}$ at the design frequency and is shown in Fig. 7. 


\section{CONCLUSIONS}

The design and performance characteristics of a CPW/Stripline feed network have been presented. A seven patch hexagonal CP subarray fed with this feed network has demonstrated excellent $C P$ patterns.

\section{REFERENCES}

1. Y. T. Lo, B. Engst and R. Q. Lee, "Simple Design Formulas for Circularly Polarized Microstrip Antennas," IEE Proc., Microwaves, Antennas and Propagation, Vol.135, Pt.H, No.3, pp.213-215, June 1988.

2. R. N. Simons and G. E. Ponchak, "Coax-to-Channelized Coplanar Waveguide In-Phase N-Way, Radial Power Divider," Electronics Letters., Vol.26, No.11, pp.754-755, May 1990. 


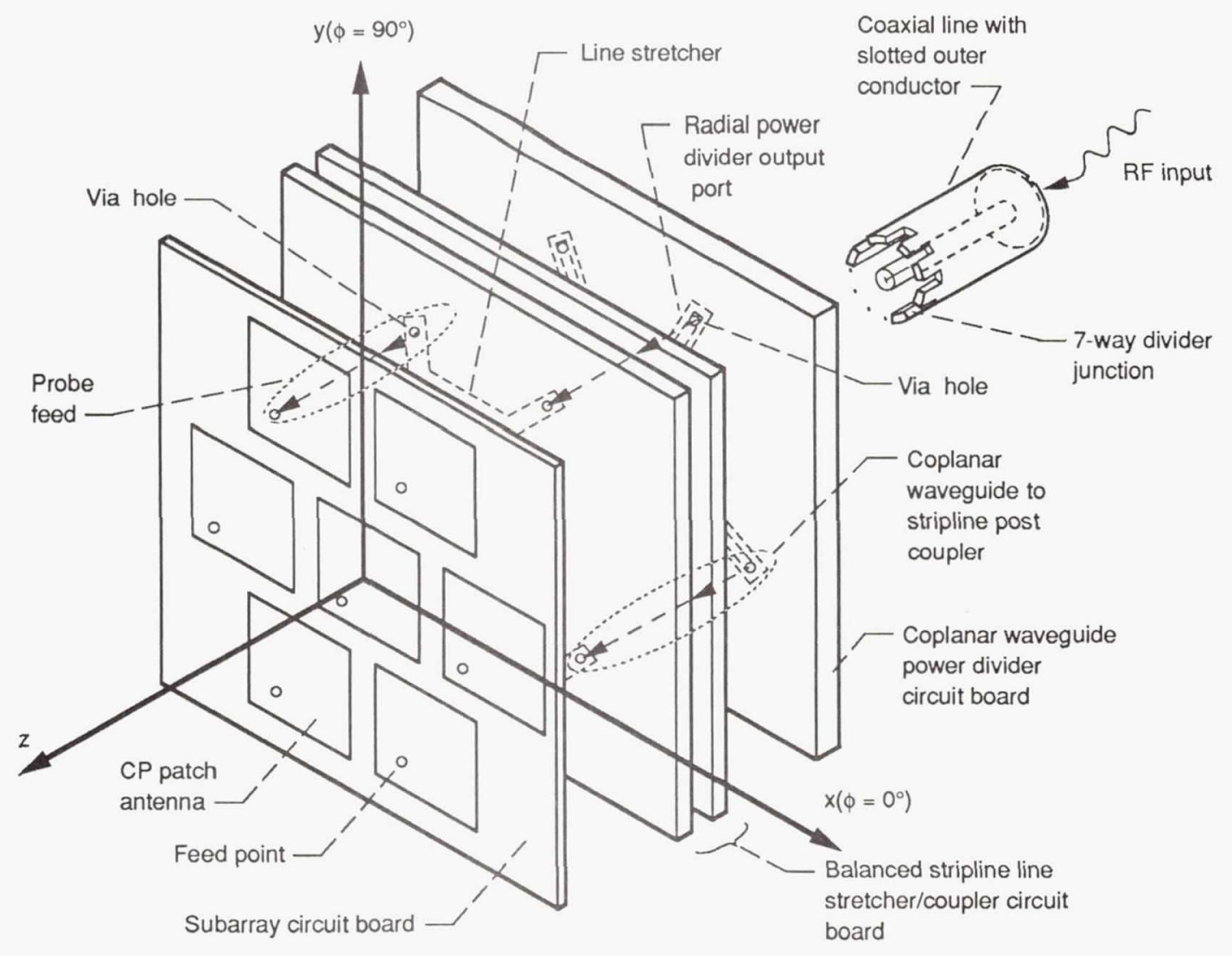

Figure 1.-Array schematic.

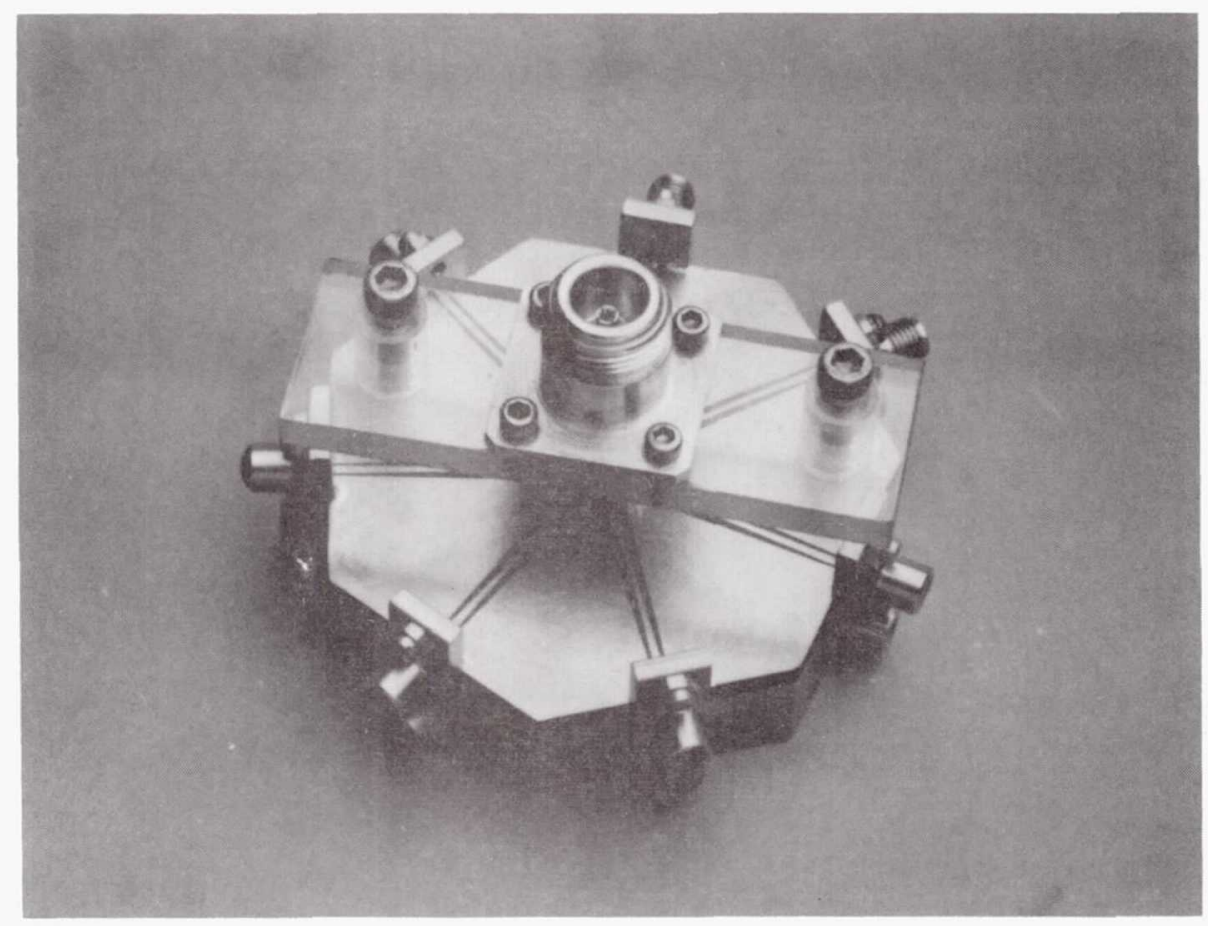

Figure 2.-Radial coax-to-CPW 1:7 power divider. 


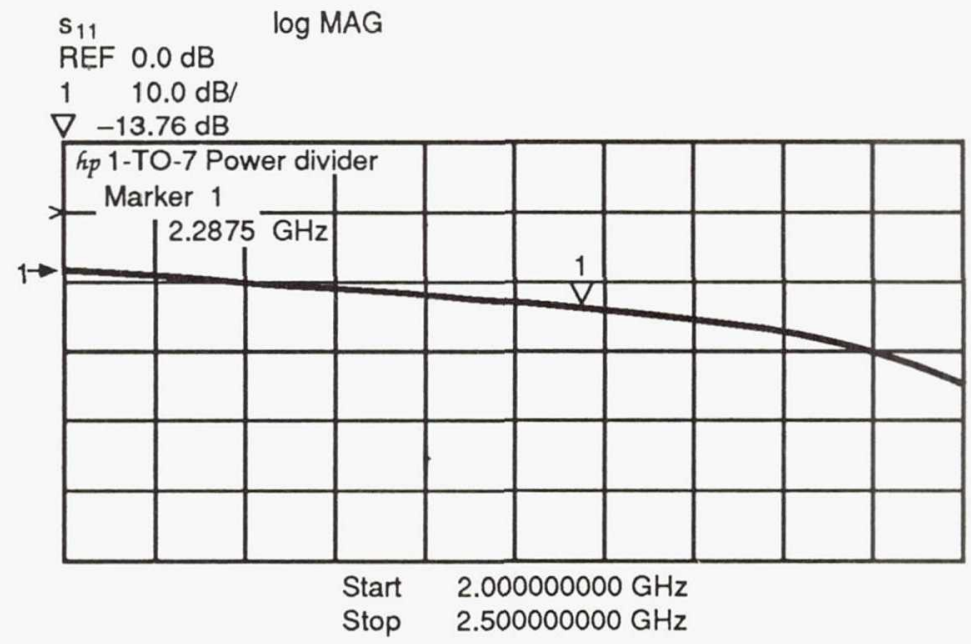

(a) Measured reflection coefficient at the coaxial input port.

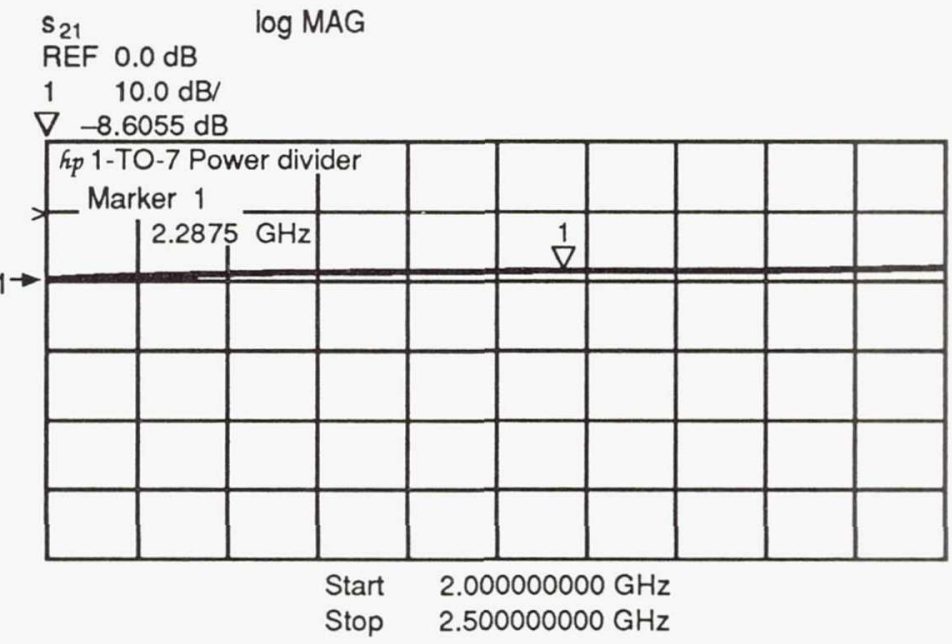

(b) Measured power coupled to output port.

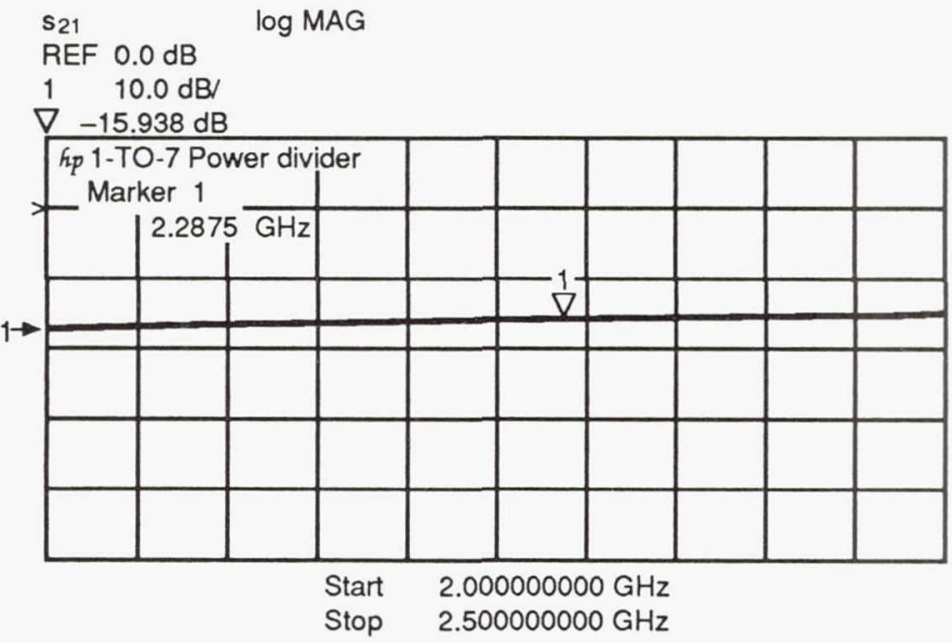

(c) Measured isolation between output ports.

Figure 3.-Coax-to-coplanar waveguide 1:7 power divider. 


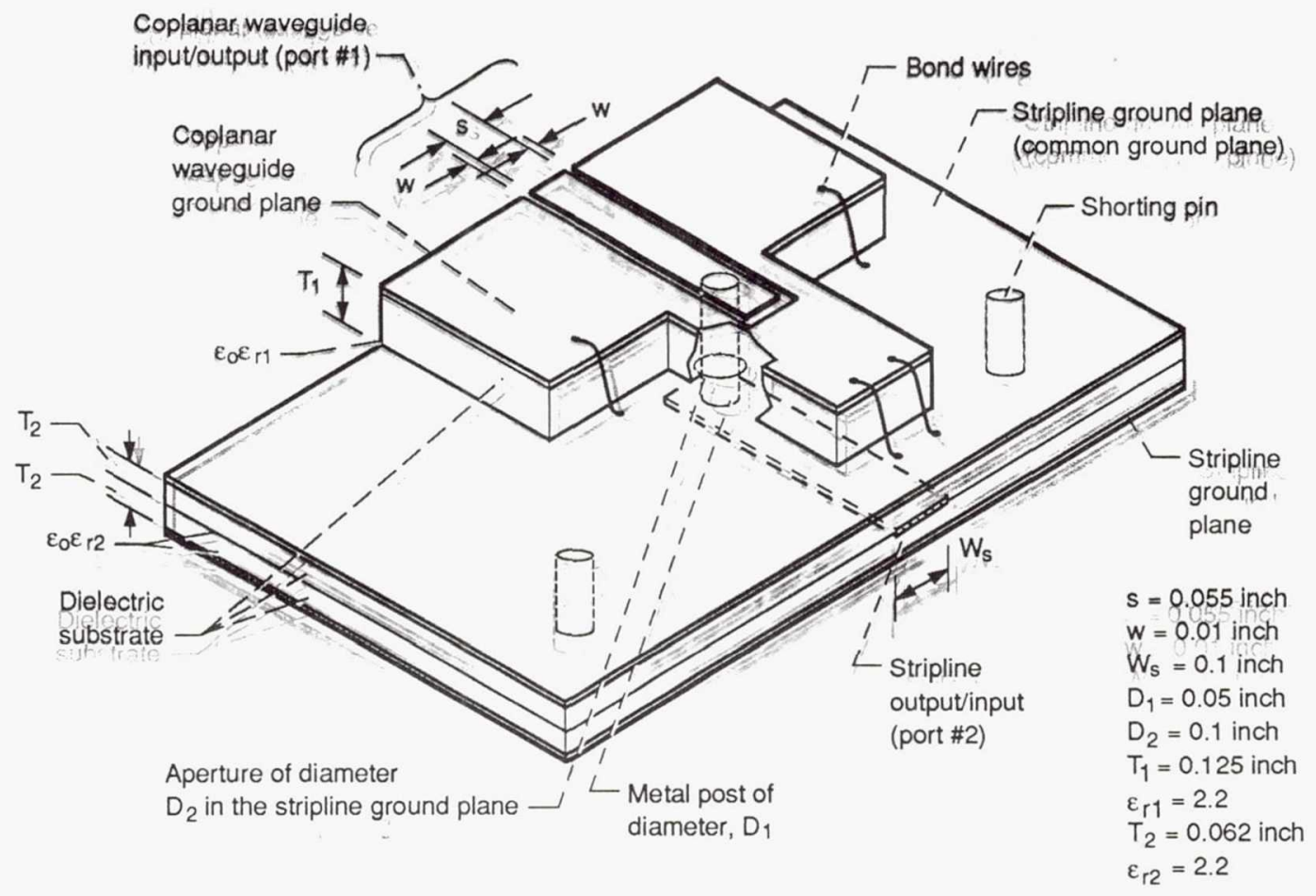

(a) CPW-to-stripline post coupler.

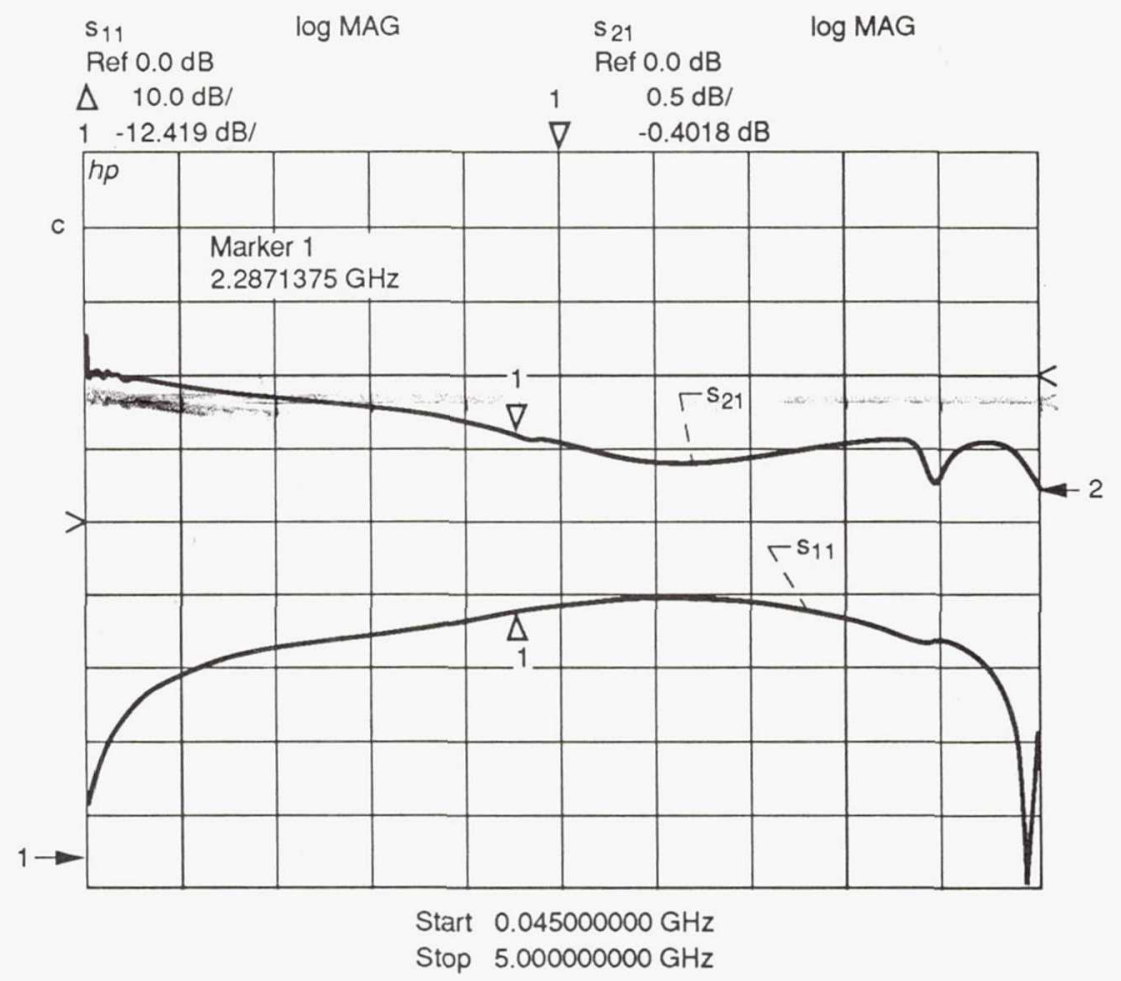

(b) Measured coupler characteristics.

Figure 4. 


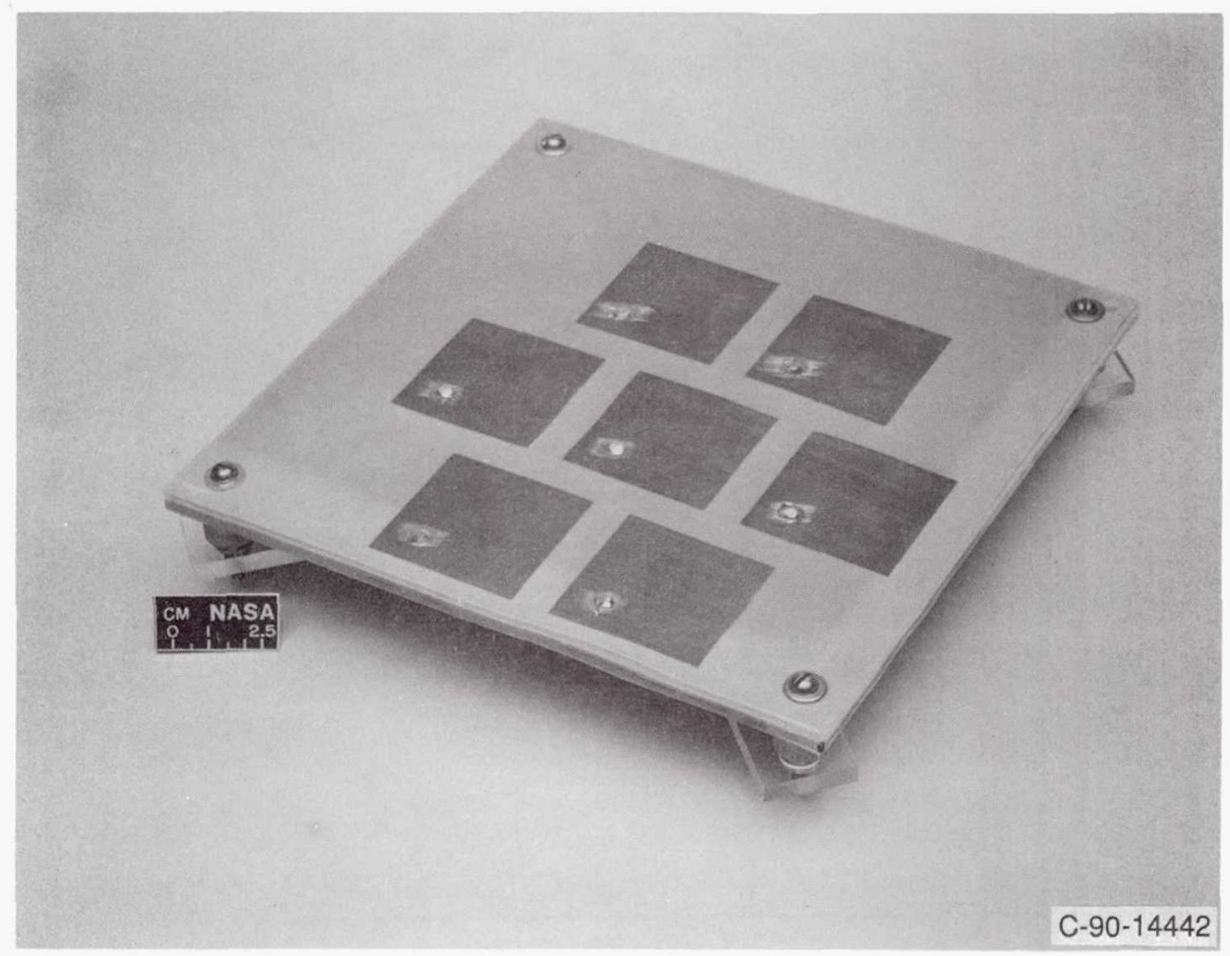

(a) Assembled array antenna.

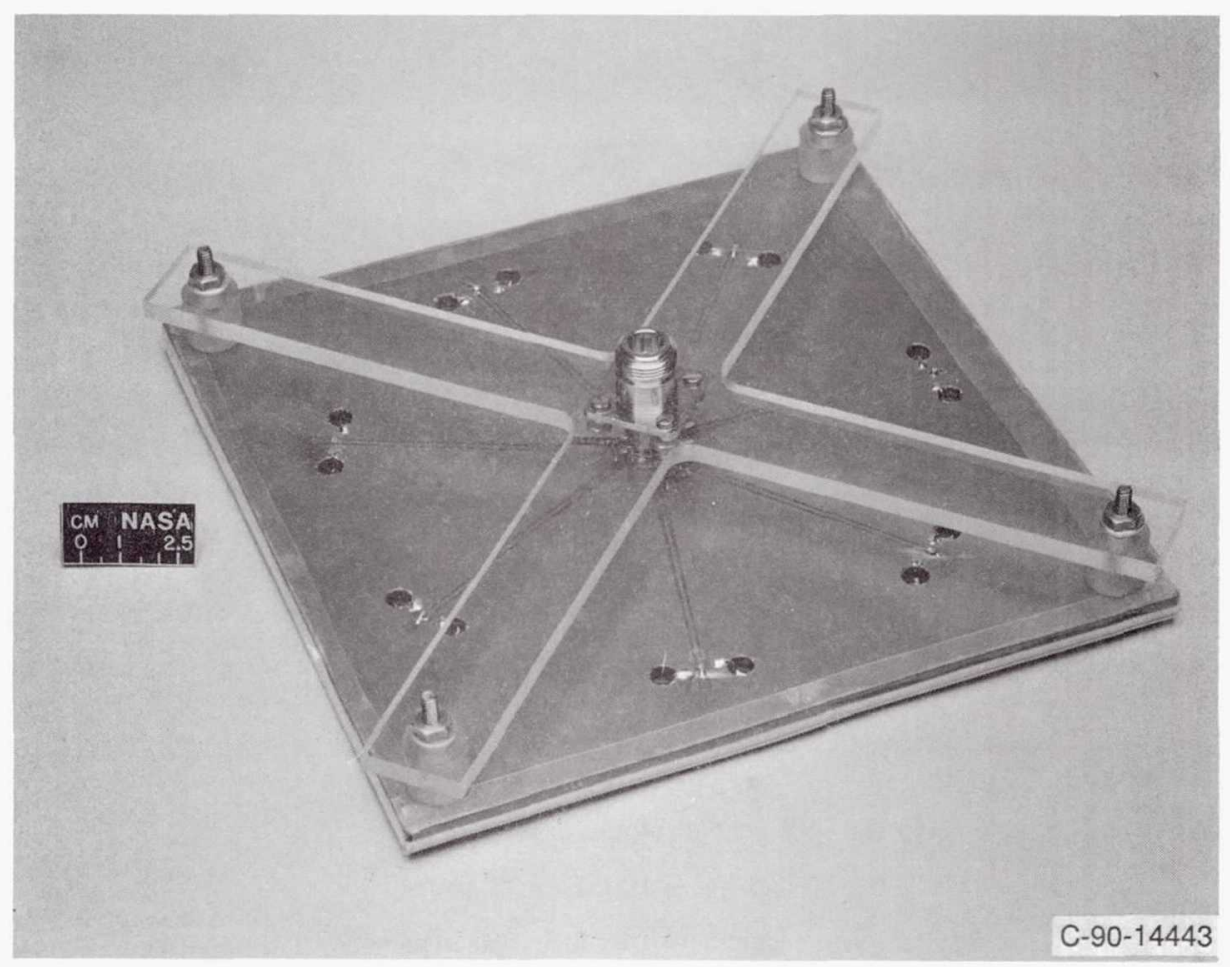

(b) Feed and power divider network.

Figure 5. 


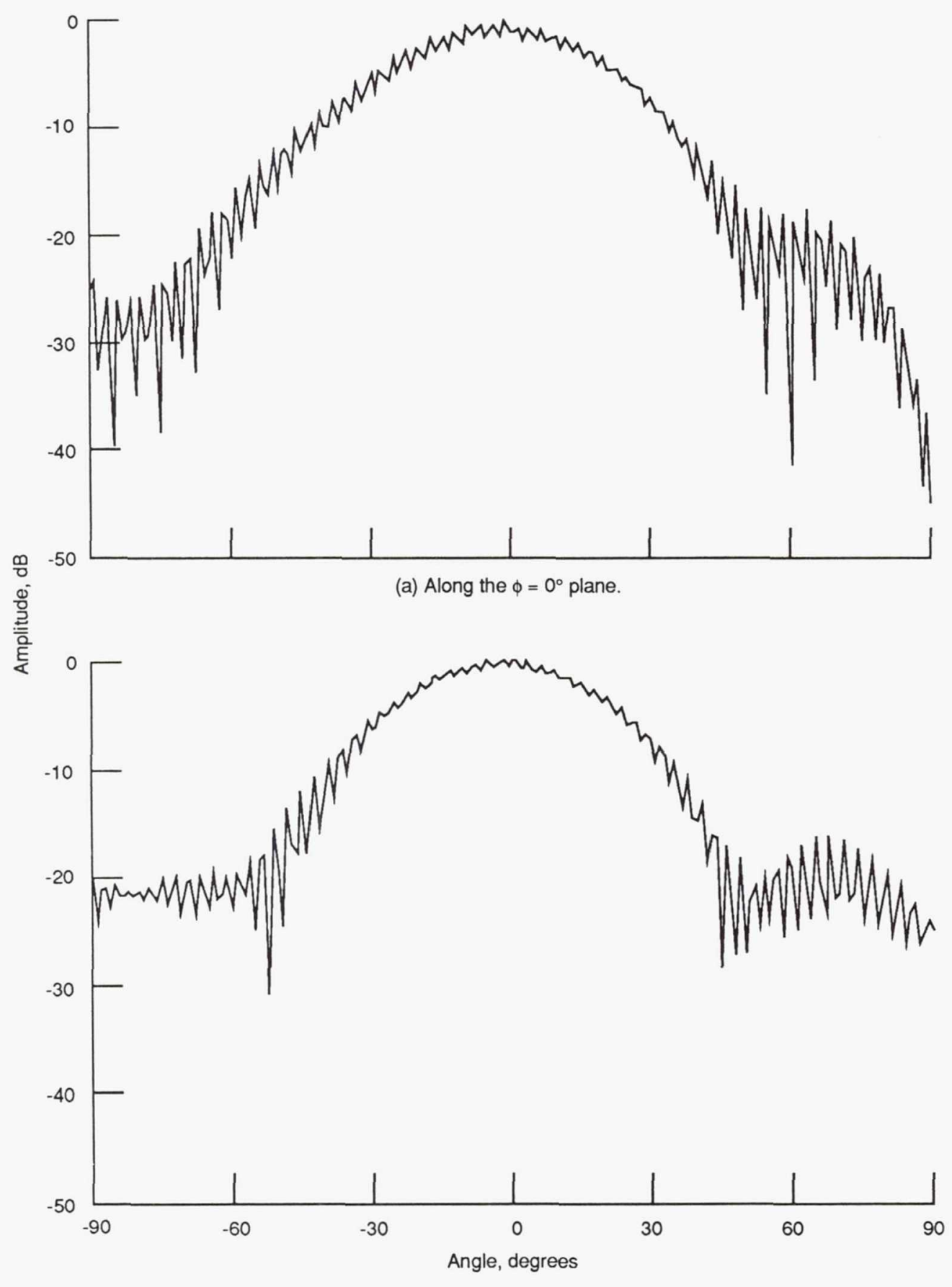

(b) Along the $\phi=90^{\circ}$ plane.

Figure 6.-Measured radiation patterns. 


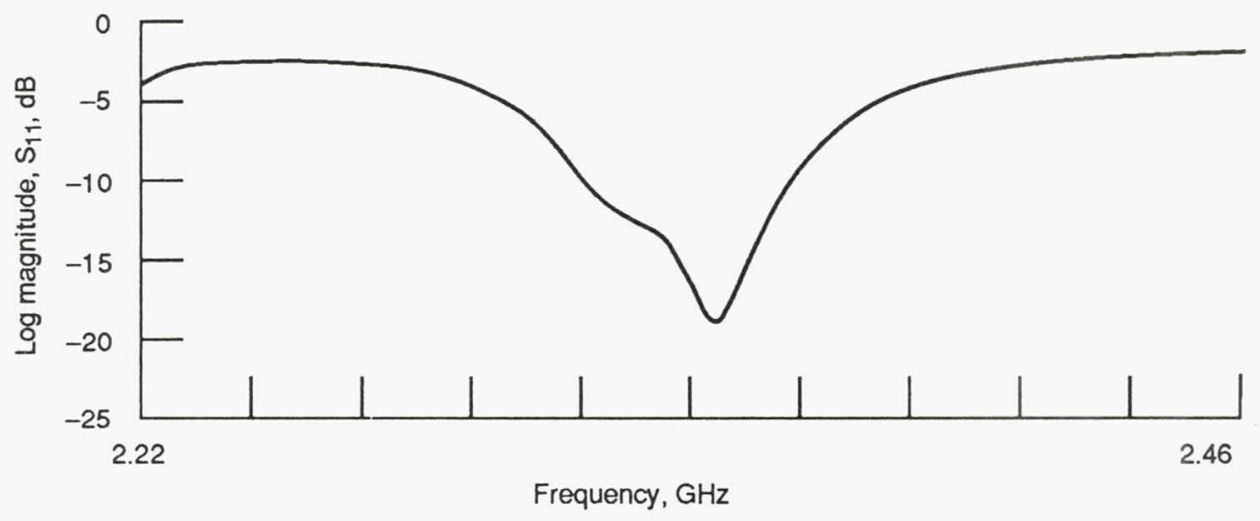

Figure 7.-Measured return loss at the coaxial input port. 


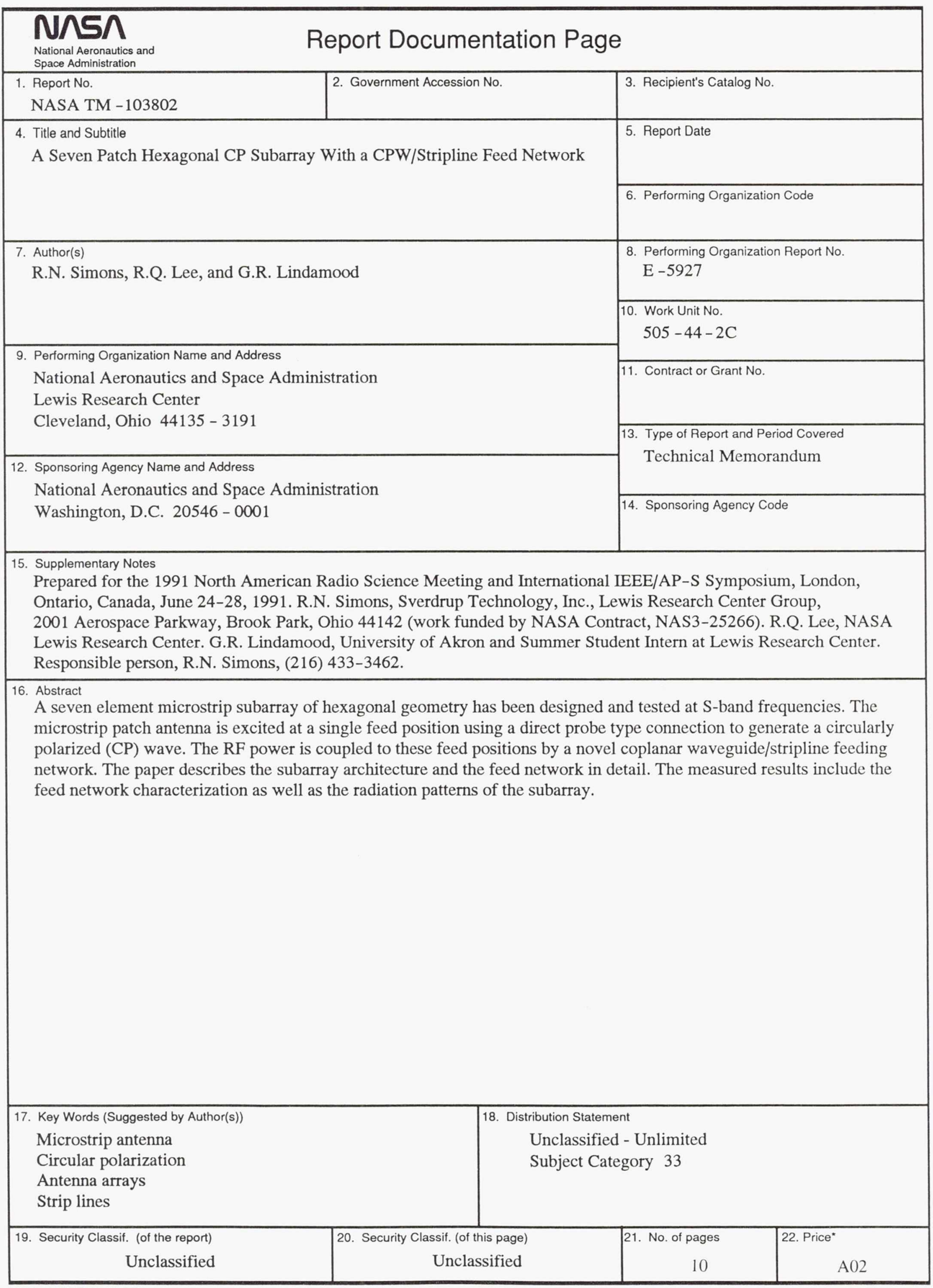

